\title{
Interdisciplinary Teamwork: Student Differences and Teaching Implications
}

\author{
Janet R. Buelow, University of Illinois, USA \\ Rod McAdams, University of Kansas, USA \\ Alice Adams, University of Alabama at Birmingham, USA \\ Leigh E. Rich, University of Colorado at Denver, USA
}

\begin{abstract}
Teamwork with individuals from multiple disciplines is recognized as a significant skill necessary for professional employment. While a variety of teaching methods for students in health care professions have been investigated and found to be generally effective in improving interdisciplinary team skills, one field - health administration - has not been included in these studies. The research presented here used two standardized instruments (with seven distinct subscales) to compare perceptions of health care administration students and clinical students regarding interdisciplinary teamwork. Three attitudes toward interdisciplinary health care teams were similar among all students - shared leadership, perceived need for cooperation, and understanding others' values. Significant differences between administration and clinical students were found in four areas. Health administration students exhibited lower scores for: 1) believing in the value of teamwork, 2) recognizing teamwork efficiency, 3) believing their profession was perceived as competent by other health care professionals, and 4) recognizing their own lack of cooperation in teamwork. These findings reveal the diverse cultures among health care professionals and invite educators to consider the diversity of their students when implementing interdisciplinary team-teaching techniques and methods.
\end{abstract}

Keywords: Teamwork; interdisciplinary teams; health care administration students; clinical students; interdisciplinary education

\section{INTRODUCTION}

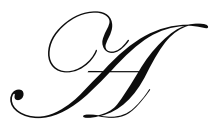

merica's most successful corporations recognize the importance of teamwork as a significant component to their success. One industry that offers particularly strong evidence of the effectiveness of interdisciplinary teams is health care. A randomized control study by Rubenstein and colleagues (1984) demonstrated positive outcomes among elderly patients as a result of interdisciplinary teamwork, including decreased mortality, more accurate diagnosis, improved functioning, and decreased rates of nursing home placement. More recent findings in hospitals, intensive care units, rehabilitation centers, and mental health care settings have identified similar outcomes, such as fewer hospitalizations, decreased costs, significant reductions in patient readmission rates, and improvements in mental health standardized exams (Burns, Nichols, Martindale-Adams, \& Graney, 2000; Sommers, Marton, Barbaccia, \& Randolph, 2000; Boult, Boult, Morishita, Smith, \& Kane, 1998; Eng, Pedulla, Eleazer, McCann, \& Fox, 1997; Ryan, 1996; Stuck, Sui, Wieland, Adams, \& Rubenstein, 1993; Baggs, Ryan, Phelps, Richeson, \& Johnson, 1992; Keith, 1991; Diller, 1990; and Knaus, Draper, Wagner, \& Zimmerman, 1986).

This study compares the perspectives of health care administration students and clinical students regarding components of interdisciplinary teams. Despite evidence that health care administration students are beginning to be included in interdisciplinary educational experiences, it is unclear whether all students within the health professions approach teamwork with similar mindsets. As a profession, health care administration is instrumental in supporting effective teamwork and collaborative skills are recognized as core administration competencies. This exploratory study aims to identify existing professional differences and, consequently, the need for enhanced teaching practices. 


\section{Background On Interdisciplinary Education In Health Care Professions}

Interprofessional education has been defined as two or more professions learning with, from, and about one another (Cooper, Carlisle, Gibbs, \& Watkins, 2001). Building interdisciplinary teamwork among health care professionals involves more than coordinating services. Professionals must integrate their understandings, determine mutual goals, and work with limited resources. A limited body of research has found that health care students educated in interdisciplinary teamwork become more collaborative professionals in the workplace (Buelow et al., 2008; Howell, Devine, \& Protsman, 2004; Ruebling et al., 2000).

Various teaching strategies to promote interdisciplinary education for university students are reported in the literature (Lavin et al., 2001). In the United Kingdom, Cooper and colleagues (2001) surveyed undergraduate health care students about their educational experiences in interdisciplinary teamwork. The dominant teaching methods involved small groups, case studies, and experiential learning; however, traditional didactic teaching still represented more than one-third of the interventions. Outcomes included students' improved knowledge of different professional roles and awareness of the concept of interdisciplinary teams. Similarly, Pirrie et al. (1999), also from the United Kingdom, conducted a two-year evaluation of interdisciplinary education among health care students, course organizers, and professionals from ten universities and four cooperating health care sites. The authors concluded that interdisciplinary education contributed to the professional development of health care students; however, it was most effective for graduate students due to their greater sense of professional identity and confidence in exchanging ideas. Factors necessary for successful interdisciplinary education involved convincing faculty and students of its importance and having educational leaders committed to working collaboratively. Factors inhibiting interdisciplinary education included a need to maintain professional identity, excessive requirements of national boards, disparities in student numbers among health professions, a lack of suitable accommodations for teaching large numbers of students, and coordination across disciplines with different timetables.

In the United States, education for building interdisciplinary teamwork has focused primarily on partnerships between community health care institutions and universities, with considerable funding by private foundations. In one study, follow-up evaluations after the funding phase revealed universities had increased the number of students and disciplines participating in their programs as well as developed new lines of communication among disciplines, universities, and health care organizations (Harris, Henry, Bland, Starnaman, \& Voytek, 2003). However, barriers existed similar to those found in the U.K.-based studies: Community partners felt universities operated in bureaucratic ways that hindered interdisciplinary cooperation; university departments were fragmented, compartmentalized, and politicized; and the burden of coordinating across health care disciplines too often fell on community partners rather than on university faculty, who frequently were unaware of each other or unwilling to work together (Harris et al., 2003).

Researchers at a few universities have stressed the benefits of educating allied health and medical students about interdisciplinary teamwork using structured, problem-based learning. Among the more popular and promising methods have been teams of students from different disciplines working together on clinical case simulations using written scenarios, real clients, or a combination of both (Sandmire \& Boyce, 2004; Howell et al., 2004). Anderson (2005) encouraged early training of medical school students with real-life clinical scenarios and environments using virtual or live substitutes for real patients. This type of training often is followed by "facilitated debriefings" by faculty to evaluate student success of performance targets. Simulation-based learning provides students with opportunities to achieve clinical competencies in a safe environment, allowing them to make mistakes without risk of real-world consequences (i.e., harming actual patients).

A limited number of researchers have applied problem- and simulation-based learning to interdisciplinary training of students serving geriatric clients. The Hartford Foundation, for example, supported a Geriatric Interdisciplinary Team Training program in which working health care professionals and college students convened periodically for interdisciplinary training using experiential exercises, training videos, and live clinical case simulations in which trained actors portrayed clinical manifestations of actual patients (Howe, Hyer, Mellor, Lindeman, \& Luptak, 2001). While improved student knowledge was achieved, organizers nevertheless identified several barriers to employing their teaching methods, including scheduling conflicts, diverse skill levels, inadequate collaboration between colleges and work settings, and differences in professional cultures. 


\section{METHODS}

To study the attitudes and beliefs regarding interdisciplinary teamwork students enrolled in seven different disciplines and enrolled in different courses at a southeastern public university completed a survey during the 2010 spring semester. The survey was anonymous and required minimal demographic information (profession of study, gender, and age). Students were asked to rate 39 statements using a 6-point Likert scale (strongly disagree to strongly agree). Items on the survey came from two pre-validated and widely used interprofessional instruments: the Interdisciplinary Education Perception Scale or IEPS (Luecht, Madsen, Taugher, \& Petterson, 1990) and the Attitudes Toward Health Care Teams Scale or ATHCTS (Heinemann, Schmitt, Farrell, \& Brallier, 1999).These instruments were selected because they have been found to provide a robust measure of attitudes and perceptions about interdisciplinary teams, and, because of their wide use, findings can be compared with other studies and institutions.

Table 1 provides a description of the sample of students who participated. A total of 115 students completed the survey - 32 undergraduate clinical, 33 graduate clinical, 26 undergraduate health administration, and 24 graduate health administration. The undergraduate clinical students hailed primarily from medical technology and respiratory therapy and the graduate clinical students from nursing and speech-language pathology. The health administration students were enrolled in the undergraduate or graduate program within accredited health services administration degree programs.

Table 1: Demographic Characteristics of Students

\begin{tabular}{|c|c|c|c|}
\hline & $N=115$ & $\%$ Female & $\begin{array}{r}\text { Mean Age in Years } \\
\text { (standard deviation) }\end{array}$ \\
\hline \multicolumn{4}{|c|}{ Undergraduate Students } \\
\hline Clinical $^{1}$ & 32 & $75 \%$ & $26.5(8.33)$ \\
\hline Administration & 26 & $89 \%$ & $26.0(6.55)$ \\
\hline \multicolumn{4}{|c|}{ Graduate Students } \\
\hline Clinical $^{2}$ & 33 & $88 \%$ & 35.9 (11.12) \\
\hline Administration & 24 & $42 \%$ & $30.5(8.80)$ \\
\hline
\end{tabular}

The Attitudes Toward Health Care Teams Scale (ATHCTS) is composed of 21 items about which respondents note their level of disagreement or agreement (strongly disagree to strongly agree). These items are divided into three subscales: team value, team efficiency, and shared leadership. The instrument has been tested, shown to be valid and reliable, and used in multisite, federally funded research with employed health professionals and health profession students (Heinemann et al., 1999; Hyer, Fairchild, Abraham, Mezey, \& Fulmer, 2000).

The first subscale, team value, measures attitudes about whether team care improves patient outcomes. The team efficiency subscale focuses on positive team characteristics such as the time required for and the productivity of meetings. The last subscale, shared leadership, reflects mutual accountability, rather than traditional physician centrality, in decision-making. Hyer and colleagues (2000), studying 913 graduate medical, nursing, social work, pharmacy, and other allied health students from eight major academic training centers, developed a student-revised version of these subscales, each demonstrating high internal consistency and validity. Hyer et al.'s revised version of the ATHCTS was used in this study.

The Interdisciplinary Education Perception Scale (IEPS) developed by Luecht, Madsen, Taugher, and Petterson (1990) consists of 18 Likert scale items and measures the professional perceptions of students relative to their own profession and other health care disciplines. Subsequent studies have used this tool with more than a thousand students (first- and second-year medical, nursing, occupational therapy, and physical therapy students), and it has exhibited strong reliability and construct validity (Rose et al., 2009; Neill, Hayward, \& Peterson, 2007). This tool measures four component subscales deemed essential to interdisciplinary practice: professional competence and autonomy; perceived need for professional cooperation; perception of actual cooperation; and understanding the value and contributions of other professions. 
The first subscale, professional competence and autonomy, measures how highly one respects his or her own profession in the sense the profession is well educated and contributes significantly to the health care field. Additionally this subscale measures how much the student believes other professions respect their given profession. The subscale, perceived need for professional cooperation, reflects perceptions of the need to work together with other professions. While the next subscale, actual cooperation, provides students' perceptions that their profession typically respects and works well with other professions. The last subscle, understanding others' values, reflects the degree of respect for contributions from all health care professions.

\section{Statistical Analysis}

Methodology from prior studies for each instrument drove the statistical analyses used here. For the ATHCTS, coding was reversed for nine items, then each item was re-coded to a zero-base, and summed scores were determined for each subscale. Using the maximum scores for each subscale (team value $=55$, team efficiency $=25$, and shared leadership=25), these sums were converted to the percentage of maximum possible scores for each subscale and the means of these scores were analyzed (Leipzig et al., 2002). Statistical differences were examined between clinical and administration students at both the undergraduate and graduate levels.

For the IEPS, individual statement response scores were summed according to the subscale composition. These sums were then multiplied by the rounded integer of the average of the factor loadings for the items in each relevant subscale (see exact methods in Luecht et al., 1990). Weighted subscale scores were checked for consistency with previous studies using this instrument (Goelen, De Clercq, Huyghens, \& Kerckhofs, 2006; Rose et al., 2009). The means for each subscale were evaluated for statistical differences using analysis of variance by program and academic status. The Statistical Package for the Social Sciences (SPSS) was used for all analyses.

\section{FINDINGS}

Although it would be premature to draw firm conclusions from the following results because sample groups were small and may lack the statistical power to reflect true differences in scores (Type II error), both the subscale scores and the individual items within these measures were examined for insights into students' perceptions.

\section{Shared Leadership, Cooperation, Understanding Others}

As presented in Tables 2 and 3, a total of seven subscales represent different aspects of effective teamwork. Students, regardless of their professional major or academic level, did not significantly differ in their perspectives with regard to three subscales - shared leadership, perceived need for cooperation, and understanding others' values. For shared leadership, between $40 \%$ and $53 \%$ of the students strongly supported shared versus physician-led teamwork. The other two subscales were measured with mean scores. For "need for cooperation", mean scores ranged from 58 to 68 out of a possible total score of 72, reflecting relatively high ratings. For "understanding others' values", again out of a possible maximum score of 72, mean scores ranged from 48 to 53, reflecting slightly lower ratings. These three measures are significant contributors to effective teamwork. Overall, they reveal a mutual appreciation and respect for the contributions of diverse professions. Student scores reflected no significant differences between clinical and administration majors. The individual statements within each of these subscales can be found in Appendices A and B.

Table 2: Attitudes toward Health Care Teams Subscales

\begin{tabular}{|c|c|c|c|c|}
\hline \multicolumn{5}{|c|}{ Mean Percent of Maximum Scores ( standard error) } \\
\hline Undergraduate Students & $\mathrm{N}=115$ & Shared Leadership & Team Value & Team Efficiency \\
\hline Clinicians & 32 & $40.5(2.8)$ & $76.1(2.0)$ & $60.3(2.9)$ \\
\hline Administration & 26 & $52.6(3.0)$ & $66.2(1.9) * *$ & $53.1(2.9)$ \\
\hline Graduate Students & \multicolumn{5}{|c|}{ *) } & $82.6(1.7)$ & $71.0(2.4)$ \\
\hline Clinicians & 33 & $53.7(2.9)$ & $80.2(2.6)$ & $57.3(3.5) * *$ \\
\hline Administration & 24 & $47.2(2.3)$ &
\end{tabular}


Table 3: Interdisciplinary Education Perception Subscales*

\begin{tabular}{|c|c|c|c|c|c|}
\hline \multirow[b]{2}{*}{ Undergraduate Students } & \multirow[b]{2}{*}{$\mathrm{N}=115$} & \multicolumn{4}{|c|}{ Mean Scores (standard deviation) } \\
\hline & & $\begin{array}{l}\text { Competence/ } \\
\text { Autonomy }\end{array}$ & $\begin{array}{c}\text { Need for } \\
\text { Cooperation }\end{array}$ & $\begin{array}{c}\text { Actual } \\
\text { Cooperation }\end{array}$ & $\begin{array}{l}\text { Understanding } \\
\text { Others' Values }\end{array}$ \\
\hline Clinical & 32 & $78.2(9.3)$ & $60.1(10.3)$ & $76.6(8.4)$ & $48.8(6.0)$ \\
\hline Administration & 26 & $71.4(8.7) * *$ & $58.2(13.2)$ & $70.5(7.9) * *$ & $48.2(7.8)$ \\
\hline \multicolumn{6}{|l|}{ Graduate Students } \\
\hline Clinical & 33 & $81.3(7.5)$ & $68.3(4.8)$ & $78.1(7.4)$ & $52.8(7.3)$ \\
\hline Administration & 24 & $74.5(10.2) * *$ & $65.1(9.8)$ & $71.7(8.9) * *$ & $50.4(7.6)$ \\
\hline
\end{tabular}

Scores summarized by mean (standard deviation). Higher scores indicate more positive attitudes toward interprofessional cooperation. Maximum scores for competency/autonomy $=96$; need for cooperation $=72$; actual cooperation $=90$; and understanding others' values $=72$.

$* * \mathrm{p} \leq .001$

Students did significantly differ in four subscales: team value, team efficiency, professional competence, and perceptions of actual cooperation while working on teams. These subscale scores are described below.

\section{Team Value}

Team value, a subscale of 11 items on the ATHCTS, is interpreted as valuing interdisciplinary teams and recognizing their ability to improve patient care. As Table 2 reveals, more than $80 \%$ of graduate students (both clinical and administration) strongly valued teams. However, there were significant differences among undergraduate students' perceptions. Fewer administration students (66\%) compared to clinical students (76\%) provided the maximum ratings for valuing teams. The most notable differences in student perspectives included believing teams: (a) make the delivery of care more efficient; (b) help meet the needs of patients and families; and (c) help avoid errors in delivering care. Fewer administration than clinical students believed each of these statements (see appendix A).

\section{Team Efficiency}

The subscale team efficiency is the belief that time invested in teamwork truly results in better care and hence is worthwhile. Between $53 \%$ and $60 \%$ of undergraduate students strongly believed this (see Table 2). For the graduate students, $71 \%$ of clinical students strongly believed in the efficiency of teams, while significantly fewer administration students (57\%) provided maximum scores for this subscale. Examining the items within this subscale, the biggest gap in perspectives among students occurred in the area of patient satisfaction from teamwork. Only $63 \%$ of administration students versus $97 \%$ of clinical students believed patients were more satisfied with their care when a team provides it. Another item with particularly low agreement ratings was the statement, "Developing an interdisciplinary patient care plan is excessively time consuming." Although this item's score was reversed to contribute to the overall scale score, as a single item $24 \%$ of clinical versus $50 \%$ of administration students agreed (see appendix A).

\section{Professional Competence and Autonomy}

This measurement pertains to the competency and autonomy students feel they have within their own profession as well as the respect they are shown by other professions. As Table 3 indicates, mean scores for this area were relatively high for all students (ranging from 71 to 81 with 96 as the maximum possible mean score). There were, however, significant differences among administration and clinical students. At both the undergraduate and graduate levels, administration students had significantly lower scores than their clinical peers. From a total of eight items on this subscale, two specific beliefs received the lowest ratings from graduate administration students: "Individuals in other professions think highly of my profession" (67\%) and "Individuals in my profession are extremely competent" (63\%). For undergraduate administration students, items with the lowest scores included: "Individuals in other professions think highly of my profession" (35\%) and "Individuals in my profession are well trained" (58\%). Items demonstrating the biggest gaps in beliefs between clinical and administration students were: "Individuals in my profession are very positive about their contributions and accomplishments" and "Individuals in my profession are extremely competent" (see appendix B). 


\section{Actual Cooperation on Teams}

This subscale represents how students believe members of their profession typically behave as part of a health care team. Administration students provided significantly lower scores with regard to cooperation than their clinical peers (see Table 3). With a maximum possible value of 90 , mean scores for administration students ranged from 70 to 71 , while mean scores for clinical students ranged from 77 to 78 . The two items administration students agreed with the least included: "Individuals in my profession are able to work closely with individuals in other professions" and "Individuals in my profession are willing to share information and resources with other professions." Conversely, $94 \%$ of undergraduate clinical students and $100 \%$ of graduate clinical students agreed with the latter statement.

\section{DISCUSSION}

A steady growth of evidence indicates that interdisciplinary teams contribute to staff satisfaction, patient outcomes, and organizational fiscal bottom lines. Furthermore, there are a growing number of interdisciplinary educational experiences and courses, particularly within the health professions. Findings discussed in this paper support what previously has been found with regard to clinical students' perceptions of interdisciplinary teamwork: The majority of clinical students (and graduate students to a greater extent than undergraduate students) value interdisciplinary teams, while recognizing that they can be somewhat inefficient, and believe in both their own professional competence and ability to act in a cooperative manner when in a team environment. As other studies have noted, and these findings corroborate, there also is room for growth as students enhance their teamwork knowledge, skills, and abilities.

This study contributes the initial findings for health administration students. Health services administration programs traditionally have been offered in three university settings: schools of medicine, public health, and health professions. Today, health services administration programs often are offered within schools of business. No matter the location within a university, accreditation requirements for health administration programs are the same. Students are trained in the fundamentals of management, strategic planning, marketing, finance, information systems, and economics, as well as many complementary areas such as interdisciplinary teamwork. Undoubtedly, health services administrators contribute significantly to health care organizations; however, their primary areas of knowledge and skills do differ fundamentally from their clinical peers.

The four significant differences identified in this study between health care administration students and clinical students are rather broad in nature. A significant percentage of health services administration students did not value health care teams to the same extent as their clinical peers. A significant proportion of these students also believed that the time required to engage in interdisciplinary teamwork was excessive, with potential outcomes not outweighing the investment. More administration than clinical students reported a lack of cooperation with other professions and lower ratings concerning their own professional competence.

While it is concerning to discover deficiencies regarding teamwork in one given health care profession (i.e., health administration), three of these four core teamwork areas (team values, efficiency, and cooperation) likely can be addressed with fundamental learning experiences as faculty become aware of these findings (and conduct research of their own). The fourth teamwork component, feelings of professional competency, however, may require separate consideration. Among graduate students, noteworthy differences exist when comparing different disciplines. Clinical graduate students generally are already working in their chosen profession and typically enter graduate programs to enhance and expand their competency. Students in health care administration, on the other hand, can begin a graduate program with highly varied backgrounds. For example,graduate health administration students come with a variety of undergraduate majors, including nursing, dental hygiene, business, economics, dentistry, and anthropology (Ginter, Menachemi, \& Morrisey, 2009). These varied backgrounds may contribute to administration graduate students' lower scores regarding feelings of professional competency. However, specific beliefs within this subscale, such as other professions not thinking highly of their profession, is concerning. One hypothesis is that those with clinical backgrounds may be carrying negative feelings from past experiences with health care administrators. This area begs for further investigation by faculty and researchers within the field. 


\section{Teaching Implications}

A review of the literature of university-based interprofessional education reveals two types of educational endeavors - courses that incorporate multiple professions, but lack didactic teamwork content or skill development (Howard, Ryan, Eudy, Mosser, \&Boyd, 2010), and courses that focus on enhancing students' interprofessional team skills and abilities, often through case studies and clinical simulations (Goelen et al., 2006; Lavin et al., 2001; Howe et al., 2001). These latter methods, while successful with clinical students, generally do not include health administration students. Thus there is a need, as this study demonstrates, to initiate recognition of professional differences and the need for expanded teaching practices within the health professions. Courses that do include students from multiple professions could maximize their opportunity to include effective interprofessional education, which is, as noted earlier in this paper, 'two or more professions learning with, from, and about one another.' Courses that already employ interprofessional learning experiences could take the needs of administration students into consideration and possibly expand current case studies and clinical simulations, or merely assignment outcomes, to include budgetary limitations and/or other managerial issues.

The standardized instruments used in this study, and by many current interprofessional programs, suggest an additional area for improving interprofessional education. These instruments measure student attitudes regarding specific aspects of effective teamwork (e.g., team value, team efficiency, shared leadership, etc.), yet a review of interprofessional education reveals that education is less able to positively influence attitudes and perceptions toward others in health services teams than enable knowledge and skills necessary for collaborative work (Hammick, Freeth, Koppel, Reeves, \& Barr, 2007). While validated, reliable instruments, such as the ATHCTS and IEPS, can continue to be used to identify and potentially change student perceptions and attitudes, it is clear that faculty and programs need to expand pre- and post-evaluation of students to include knowledge and skills of interprofessional teamwork, as well as recognition of the contributions that a variety of professionals bring to health care and its quality of services.

Lastly, faculty and programs need to recognize differences in student perceptions prior to participation in required interdisciplinary exercises or courses. To date, published models or frameworks of interprofessional education have treated all students similarly, employing the same readings, exercises, and requirements. Findings from this study suggest that introductory courses for health services administration students ought to include a variety of interprofessional teamwork opportunities so that they can start their interdisciplinary experiences on the same-level playing field as their clinical peers. The Institute of Medicine (2003) and the Pew Health Professions Commission (1998) both call for revision in the interprofessional education of health professionals, explaining that students are inadequately prepared to provide comprehensive interdisciplinary care. As leaders in this field, faculty need to recognize student differences, curriculum opportunities, and evaluation enhancements that effectively support interdisciplinary teamwork.

\section{AUTHOR INFORMATION}

Janet R. Buelow (Ph.D., University of Illinois) is an Associate Professor of Health Services Administration. Her research interests include interdisciplinary education and effective management practices in health and long-term care organizations. Janet.Buelow@armstrong.edu

Rod McAdams (Ph.D., University of Kansas) is an Associate Professor of Health Services Administration. His research interests include public financing of health care services, rural health, and health policy. $\underline{\text { Rod.McAdams@armstrong.edu }}$

Alice Adams (Ph.D., University of Alabama at Birmingham) is an Assistant Professor of Health Services Administration. Her research interests include organizational identity, leadership, team performance, and strategic management. Alice.Adams@armstrong.edu

Leigh E. Rich (Ph.D., University of Colorado at Denver) is an Assistant Professor of Public Health. Her research interests include bioethics and the law, the history and philosophy of medicine, and public health and the media. All authors are currently employed at Armstrong Atlantic State University, Department of Health Sciences, 11935 Abercorn Street, Savannah, Georgia 31419-1997. Leigh.Rich@armstrong.edu 


\section{REFERENCES}

1. Anderson, J. M. (2005). Educational perspectives: Introduction to simulation-based training. Neo Reviews, 6(9), e411-e413.

2. Baggs, J. G., Ryan, S. A., Phelps, C. E., Richeson, J. F., \& Johnson, J. E. (1992). The association between interdisciplinary collaboration and patient outcome in a medical intensive care unit. Heart and Lung: The Journal of Acute and Critical Care, 21(1), 18-24.

3. Boult, C., Boult, L., Morishita, L., Smith, S. L., \& Kane, R. L.(1998). Outpatient geriatric evaluation and management. Journal of American Geriatric Society, 46(3), 296-302.

4. Buelow, J. R., Rathsack, C., Downs, D., Jorgensen, K., Karges, J. R., \& Nelson, D. (2008). Building interdisciplinary teamwork among allied health students through live clinical case simulations. Journal of Allied Health, 37(2), e109-e123.

5. Burns, R., Nichols, L. O., Martindale-Adams, J., \& Graney, M. J. (2000). Interdisciplinary geriatric primary care evaluation and management: Two-year outcomes. Journal of the American Geriatrics Society, $48(1), 8-13$.

6. Cooper, H, Carlisle, C., Gibbs, T., \& Watkins, C. (2001). Developing an evidence base for interdisciplinary learning: A systematic review. Journal of Advanced Nursing, 35(2), 228-237.

7. Diller, L. (1990). Fostering the interdisciplinary team, fostering research in a society in transition. Archives of Physical Medicine and Rehabilitation, 71(5), 275-278.

8. Eng, C., Pedulla, J., Eleazer, G. P., McCann, R., \& Fox, N. (1997). Program of all-inclusive care for the elderly (PACE): An innovative model of integrated geriatric care and financing. Journal of the American Geriatrics Society, 45(2), 223-232.

9. Ginter, P. M., Menachemi, N., \& Morrisey, M. A. (2009). Academic health administration; who are we? what do we do? and what are our views concerning the profession? The Journal of Health Administration Education, 26(4), 259-276.

10. Goelen, G., De Clercq, G., Huyghens, L., \& Kerckhofs, E. (2006). Measuring the effect of interprofessional problem-based learning on the attitudes of undergraduate health care students. Medical Education, 40(6), 555-561.

11. Hammick, M., Freeth, D., Koppel, I., Reeves, S., \& Barr, H. (2007). A best evidence systematic review of interprofessional education: BEME Guide no. 9. Medical Teacher, 29(8), 735-751.

12. Harris, D. L., Henry, R. C., Bland, C. J., Starnaman, S. M., \& Voytek, K. L. (2003). Lessons learned from implementing multidisciplinary health professions educational models in community settings. Journal of Interprofessional Care, 17(1), 7-20.

13. Heinemann, G. D., Schmitt, M. H., Farrell, M. P., \& Brallier, S. A. (1999). Development of an Attitudes Toward Health Care Teams Scale. Evaluation and the Health Professions, 22(1):123-142.

14. Howard, D., Ryan, K., Eudy, R., Mosser, G., \& Boyd, K. (2010).Critical decision points in designing interprofessional education. The Journal of Health Administration Education, 27(2), 135-144.

15. Howe, J. L., Hyer, K,, Mellor, D. J., Lindeman, D., \& Luptak, M. (2001). Educational approaches for preparing social work students for interdisciplinary teamwork on geriatric health care teams. Social Work in Health Care, 32(4), 19-42.

16. Howell, D., Devine, N., \& Protsman, L. (2004). An interdisciplinary learning experience through allied clinical practice with community volunteers. Journal of Allied Health, 33(3), 205-209.

17. Hyer, K., Fairchild, S., Abraham, I., Mezey, M., \& Fulmer, T. (2000). Measuring attitudes related to interdisciplinary training: Revisiting the Heinemann, Schmitt and Farrell "Attitudes Toward Health Care Teams" scale. Journal of Interprofessional Care, 14(3), 249-258.

18. Institute of Medicine of the National Academies. (2003, April 18). Health professions education: A bridge to quality (National Academies Press). Washington, DC: A. C. Greiner \& E. Knebe (Eds.).

19. Keith, R. A. (1991). The comprehensive treatment team in rehabilitation. Archives of Physical Medicine and Rehabilitation, 72(5), 269-274.

20. Knaus, W. A., Draper, E. A., Wagner, D. P., \& Zimmerman, J. E. (1986). An evaluation of outcomes from intensive care in major medical centers. Annals of Internal Medicine, 104(3), 410-418.

21. Lavin, M., Ruebling, I., Banks, R., Block, L., Counte, M., Furman, G., Miller, P., Reese, C., Viehmann, V., \& Holt, J. (2001). Interdisciplinary health professional education: A historical review. Advances in Health Sciences Education, 6(1), 25-47. 
22. Leipzig, R. M., Hyer, K., Ek, K., Wallenstein, S., Vezina, M. L., Fairchild, S., Cassel, C. K., \& Howe, J. L. (2002). Attitudes toward working on interdisciplinary health care teams: A comparison by discipline. Journal of the American Geriatrics Society, 50(6), 1141-1148.

23. Luecht, R. M., Madsen, M. K., Taugher, M. P., \& Petterson, B. J. (1990). Assessing professional perceptions: Design and validation of an Interdisciplinary Education Perception Scale. Journal of Allied Health, 19(2), 181-191.

24. Neill, M., Hayward, K. S., \& Peterson, T. (2007). Students' perceptions of the interprofessional team in practice through the application of servant leadership principles. Journal of Interprofessional Care, 21(4), 425-432.

25. Pew Health Professions Commission. (1998). Recreating health professional practice for a new century. San Francisco, CA: E. H. O’Neil \& the Pew Health Professions Committee.

26. Pirrie, A., Hamilton, S., \& Wilson, V. (1999). Multidisciplinary education: Some issues and concerns. Educational Research, 41(3), 301-314.

27. Rose, M. A., Smith, K., Veloski, J. J., Lyons, K. J., Umland, E., \& Arenson, C. A. (2009). Attitudes of students in medicine, nursing, occupational therapy, and physical therapy toward interprofessional education. Journal of Allied Health, 38(4), 196-2001.

28. Ruebling, I., Lavin, M. A., Banks, R,, Block, L., Counte, M., Furman, G., Miller, P., Reese, C., \& Viehmann, V. (2000). Facilitating factors for, barriers to, and outcomes of interdisciplinary education projects in the health sciences. Journal of Allied Health, 29(3), 165-170.

29. Rubenstein, L. Z., Josephson, K. R., Wieland, G. D., English, P. A., Sayre, J. A., \& Kane, R. L. (1984). Effectiveness of a geriatric evaluation unit—a randomized clinical trial. New England Journal of Medicine, $311,1664-1670$.

30. Ryan, D. P. (1996). A history of teamwork in mental health and its implications for teamwork training in gerontology. Educational Gerontology, 22(5), 411-431.

31. Sandmire, D. A., \& Boyce, P. F. (2004). Pairing of opposite learning styles among allied health students: Effects on collaborative performance. Journal of Allied Health, 33(2), 156-163.

32. Sommers, L. S., Marton, K. I., Barbaccia, J. C., \& Randolph, J. (2000). Physician, nurse, and social worker collaboration in primary care for chronically ill seniors. Archives of Internal Medicine, 160(12), 1825-1833.

33. Stuck, A. E., Sui, A. L., Wieland, G. D., Adams, J., \& Rubenstein, L. Z. (1993). Comprehensive geriatric assessment: A meta-analysis of controlled trials. Lancet, 342(8878), 1032-1036. 


\section{APPENDIX A}

\section{Percent of Students Indicating Any Kind of Agreement on ATHCTS Items ${ }^{1}$}

\section{Undergraduates \\ Clinicians Health}

Team Value

The team approach ....

improves the quality of care to patients.

makes the delivery of care more efficient

permits professionals to meet the needs of family and patients.

helps to understand the work of other health professionals.

Professionals working on a team ...

keep enthusiastic \& interested in their jobs.

are more responsive to the needs of patients.

give and take to facilitate better patient care decisions.

Team meetings foster communication among different disciplines.

Patients receiving team care are more likely treated holistically.

Developing a care plan with other professionals avoids errors.

Patients receiving team care are better prepared for discharge.

Team Efficiency

Working in teams . . .

unnecessarily complicates things. ${ }^{2}$

much time is wasted translating jargon from other disciplines. ${ }^{2}$

to develop a patient care plan is excessively time consuming. ${ }^{2}$

Patients are less satisfied when their care is provided by a team. ${ }^{2}$

Generally time required for team meetings could be better spent. ${ }^{2}$

Physician's shared role on team

Physicians ... .

have the right to alter care plans developed by the team. ${ }^{2}$

should not always have the final word in team decisions.

have ultimate responsibility for decisions made by the team. ${ }^{2}$

are natural team leaders. ${ }^{2}$

${ }^{1}$ These are abbreviated statements.

2 The scoring on this statement was reversed for scale scores.
32

Graduates

Clinicians Health

$33 \quad$ Adm

26

$100 \% \quad 100 \% \quad 100 \% \quad 100 \%$

$\begin{array}{llll}94 & 77 & 97 & 83\end{array}$

$\begin{array}{llll}97 & 77 & 100 & 92\end{array}$

$\begin{array}{llll}100 & 89 & 100 & 100\end{array}$

$\begin{array}{llll}91 & 77 & 94 & 91\end{array}$

$\begin{array}{llll}72 & 73 & 82 & 83\end{array}$

$\begin{array}{llll}94 & 81 & 100 & 96\end{array}$

$\begin{array}{llll}97 & 96 & 100 & 88\end{array}$

$\begin{array}{llll}88 & 81 & 91 & 83\end{array}$

$\begin{array}{llll}94 & 81 & 97 & 88\end{array}$

$\begin{array}{llll}91 & 85 & 97 & 96\end{array}$

$\begin{array}{llll}72 \% & 42 \% & 85 \% & 63 \%\end{array}$

$\begin{array}{lllr}72 & 58 & 79 & 54\end{array}$

$\begin{array}{llll}41 & 42 & 76 & 50\end{array}$

$\begin{array}{llll}7 & 77 & 97 & 63\end{array}$

$\begin{array}{llll}66 & 54 & 73 & 58\end{array}$

\begin{tabular}{cccc} 
& & & \\
$13 \%$ & $35 \%$ & $24 \%$ & $38 \%$ \\
41 & 65 & 79 & 63 \\
59 & 65 & 66 & 54 \\
63 & 73 & 67 & 63 \\
\hline
\end{tabular}

\begin{tabular}{l}
54 \\
63 \\
58 \\
\\
\\
63 \\
54 \\
63 \\
\hline
\end{tabular}




\section{APPENDIX B}

\section{Percent of Students Indicating Any Kind of Agreement on IEPS Items ${ }^{1}$}

\begin{tabular}{|c|c|c|c|c|}
\hline & Under & raduates & Gradu & tes \\
\hline & Clinicians & HealthAdm. & Clinicians & $\begin{array}{c}\text { Health } \\
\text { Adm. }\end{array}$ \\
\hline Professional Competency and Autonomy & & & & \\
\hline Individuals in my profession ... & & & & \\
\hline are well trained. & $100 \%$ & $58 \%$ & $97 \%$ & $83 \%$ \\
\hline are extremely competent. & 91 & 65 & 85 & 63 \\
\hline have a great deal of autonomy. & 69 & 62 & 85 & 75 \\
\hline are very positive about their goals and objectives. & 88 & 69 & 88 & 83 \\
\hline very positive about their contributions \& accomplishments. & 97 & 77 & 97 & 75 \\
\hline trust each others' professional judgment. & 88 & 73 & 94 & 75 \\
\hline Other professions respect the work done by my profession. & 56 & 73 & 94 & 79 \\
\hline Other professions think highly of my profession. & 38 & 35 & 85 & 67 \\
\hline Perceived Need for Cooperation & & & & \\
\hline Individuals in my profession ... & & & & \\
\hline need to cooperate with other professions & $84 \%$ & $77 \%$ & $100 \%$ & $92 \%$ \\
\hline must depend upon the work of people in other professions. & 78 & 77 & 100 & 79 \\
\hline Perception of Actual Cooperation & & & & \\
\hline Individuals in my profession . . . & & & & \\
\hline are able to work closely with individuals in other professions. & $84 \%$ & $69 \%$ & $94 \%$ & $79 \%$ \\
\hline share information \& resources with other professions. & 94 & 77 & 100 & 71 \\
\hline have good relations with people in other professions. & 69 & 85 & 97 & 83 \\
\hline think highly of other related professions. & 84 & 85 & 94 & 92 \\
\hline work well with each other. & 100 & 85 & 97 & 79 \\
\hline Understanding Others' Values & & & & \\
\hline Individuals in my profession . . . & & & & \\
\hline have a higher status than other professions. & $3 \%$ & $12 \%$ & $28 \%$ & $29 \%$ \\
\hline understand capabilities \& contributions of other professions. & 66 & 77 & 79 & 67 \\
\hline Other professions often seek advice of people in my profession. & 75 & 60 & 85 & 67 \\
\hline
\end{tabular}

\footnotetext{
${ }^{1}$ These are abbreviated statements.
} 
NOTES 